\title{
Auscultation While Standing: A Basic and Reliable Method to Rule Out a Pathologic Heart Murmur in Children
}

\author{
Bruno Lefort, $M D^{1,2,3}$ \\ Elodie Cheyssac, $M D^{1}$ \\ Natbalie Soulé, $M D^{1}$ \\ Jacques Poinsot, MD ${ }^{1}$ \\ Marie-Catherine Vaillant, $M D^{1}$ \\ Alaeddin Nassimi MD ${ }^{4}$ \\ Alain Chantepie, $M D, P b D^{1,2}$ \\ ${ }^{1}$ Children Hospital Gatien de Clocheville, \\ University Hospital Centre of Tours, Tours, \\ France \\ ${ }^{2}$ University François Rabelais, Tours, France \\ ${ }^{3}$ INSERM UMR 1069 - Nutrition, Crois- \\ sance et Cancer, Tours, France \\ ${ }^{4}$ University Hospital Centre of Poitiers, \\ Poitiers, France
}

AC Annals Journal Club selection; see inside back cover or http://www.annfammed.org/AJC/.

Conflicts of interest: authors report none.

\section{CORRESPONDING AUTHOR}

Bruno Lefort, MD

Children Hospital Gatien de Clocheville University Hospital Centre of Tours 49 Bd Béranger

37044 Tours Cedex 01, France

lefort81@gmail.com

\begin{abstract}
PURPOSE The distinction between physiologic (innocent) and pathologic (organic) heart murmurs is not always easy in routine practice, leading too often to unnecessary cardiology referrals and expensive investigations. We aimed to test the hypothesis that the complete disappearance of murmur on standing can exclude cardiac disease in children.
\end{abstract}

METHODS From January 2014 to January 2015, we prospectively included 194 consecutive children aged 2 to 18 years who were referred for heart murmur evaluation to pediatric cardiologists at 2 French medical centers. Heart murmur characteristics while supine and then while standing were recorded, and an echocardiogram was performed.

RESULTS Overall, 30 (15\%) of the 194 children had a pathologic heart murmur as determined by an abnormal echocardiogram. Among the 100 children (51\%) who had a murmur that was present while they were supine but completely disappeared when they stood up, only 2 had a pathologic murmur, and just 1 of them needed further evaluation. Complete disappearance of the heart murmur on standing therefore excluded a pathologic murmur with a high positive predictive value of $98 \%$ and specificity of $93 \%$, albeit with a lower sensitivity of $60 \%$.

CONCLUSIONS Disappearance of a heart murmur on standing is a reliable clinical tool for ruling out pathologic heart murmurs in children aged 2 years and older. This basic clinical assessment would avoid many unnecessary referrals to cardiologists.

Ann Fam Med 2017;15:523-528. https://doi.org/10.1370/afm.2105.

\section{INTRODUCTION}

$\mathrm{H}$ eart murmur is a clinical finding currently affecting about $65 \%$ to $80 \%$ of schoolchildren ${ }^{1,2}$ and one of the most common reasons for referral to cardiologists. Most murmurs are physiologic (innocent $)^{3}$ and result from the normal pattern of blood flow through the cardiac cavities and vessels. In a few cases, however, the murmur may be the single symptom of cardiac disease, even if most congenital heart diseases are diagnosed before birth or during the first year of life. ${ }^{1}$

Differences between physiologic and pathologic murmurs are well known, ${ }^{4-9}$ but primary care physicians in family medicine or pediatricians too frequently refer their patients to pediatric cardiologists because they fear missing a heart disease diagnosis, resulting in unneeded parental anxiety, time consumption, and expensive evaluations. ${ }^{10,11}$ Several clinical features of the murmur such as intensity, timing, quality and pitch, and the presence of a click are subjective and require extensive training for use to distinguish between physiologic and pathologic murmur. A simple, objective, and robust clinical test to exclude cardiac disease in apparently healthy children could prevent many unnecessary referrals.

McLaren et $\mathrm{a}^{12}$ reported that the prevalence of physiologic heart murmur in schoolchildren was $65 \%$ when they were in a supine position, whereas it was only $15 \%$ when they were standing. To our knowledge, however, no study has demonstrated that the disappearance of murmur 
on standing can allow clinicians to rule out a murmur generated by underlying pathology. In this study, we aimed to test the disappearance of heart murmur in standing children, aged 2 years and older, as a reliable test to exclude pathologic murmur.

\section{METHODS}

Between January 2014 and January 2015, we prospectively included in our study 194 consecutive children referred to pediatric cardiologists at 2 French university hospital centers (156 referred to Tours Medical Center, 38 referred to Poitiers Medical Center) for evaluation of heart murmur. Children with genetic or systemic disorders or a family history of heart disease were excluded, as these findings on their own are sufficient to prompt referral to a specialist. All parents of the included children provided their informed consent, and the Ethics Committee for Human Research of the Tours Hospital approved the study. We excluded children aged younger than 2 years, those who could not stand for at least 1 minute, and those who had already been examined by a cardiologist or pediatric cardiologist, or who had already had an echocardiogram.

Six pediatric cardiologists participated in the study. They collected the child's personal history of cardiopulmonary symptoms: dyspnea at rest or during exercise, palpitations, syncope, and failure to thrive or grow. They also noted the characteristics of heart auscultation with an acoustic-based, nonelectronic stethoscope, first with the patient in the supine position, and then for at least 1 minute in the standing position: presence or absence of the murmur, timing (systolic, diastolic, both, continuous), location of maximal

Table 1. Clinical and Echocardiographic Characteristics of the 30 Children With Abnormal Findings on an Echocardiogram

\begin{tabular}{|c|c|c|c|c|c|c|}
\hline Patient & Sex & $\begin{array}{c}\text { Age, } \\
y\end{array}$ & $\begin{array}{l}\text { Murmur } \\
\text { While } \\
\text { Standing }\end{array}$ & $\begin{array}{c}\text { Reduction of } \\
\text { Intensity While } \\
\text { Standing }\end{array}$ & Location & Radiation \\
\hline Patient 1 & $\mathrm{M}$ & 12 & No & NA & Low to middle left sternal border & No \\
\hline Patient 2 & $\mathrm{~F}$ & 13 & No & NA & Left upper sternal border & No \\
\hline Patient 3 & $\mathrm{M}$ & 7 & Yes & No & Left upper sternal border & No \\
\hline Patient 4 & $\mathrm{~F}$ & 10 & Yes & No & Apex & Yes \\
\hline Patient 5 & $\mathrm{~F}$ & 6 & Yes & No & Apex & No \\
\hline Patient 6 & $\mathrm{~F}$ & 5 & Yes & Yes & Left upper sternal border & No \\
\hline Patient 7 & $\mathrm{~F}$ & 10 & Yes & Yes & Low to middle left sternal border & No \\
\hline Patient 8 & $\mathrm{~F}$ & 13 & Yes & Yes & Low to middle left sternal border & No \\
\hline Patient 9 & $\mathrm{~F}$ & 5 & Yes & No & Low to middle left sternal border & Yes \\
\hline Patient 10 & $\mathrm{~F}$ & 5 & Yes & Yes & Left upper sternal border & No \\
\hline Patient 11 & $\mathrm{~F}$ & 8 & Yes & No & Left upper sternal border & No \\
\hline Patient 12 & $\mathrm{~F}$ & 13 & Yes & Yes & Left upper sternal border & No \\
\hline Patient 13 & $\mathrm{~F}$ & 5 & Yes & No & Apex & No \\
\hline Patient 14 & $\mathrm{~F}$ & 6 & Yes & Yes & Low to middle left sternal border & No \\
\hline Patient 15 & $\mathrm{M}$ & 9 & Yes & No & Low to middle left sternal border & No \\
\hline Patient 16 & M & 2 & Yes & No & Low to middle left sternal border & No \\
\hline Patient 17 & $\mathrm{M}$ & 4 & Yes & No & Low to middle left sternal border & No \\
\hline Patient 18 & M & 9 & Yes & Yes & Low to middle left sternal border & Yes \\
\hline Patient 19 & $\mathrm{M}$ & 4 & Yes & Yes & Low to middle left sternal border & No \\
\hline Patient 20 & $\mathrm{M}$ & 12 & Yes & Yes & Low to middle left sternal border & Yes \\
\hline Patient 21 & $\mathrm{M}$ & 6 & Yes & No & Low to middle left sternal border & No \\
\hline Patient 22 & $\mathrm{M}$ & 2 & Yes & Yes & Low to middle left sternal border & Yes \\
\hline Patient 23 & $\mathrm{M}$ & 6 & Yes & No & Right upper sternal border & Yes \\
\hline Patient 24 & $\mathrm{M}$ & 10 & Yes & No & Right upper sternal border & Yes \\
\hline Patient 25 & $\mathrm{M}$ & 3 & Yes & No & Left upper sternal border & Yes \\
\hline Patient 26 & $\mathrm{M}$ & 5 & Yes & Yes & Right upper sternal border & Yes \\
\hline Patient 27 & $\mathrm{M}$ & 2 & Yes & No & Left upper sternal border & No \\
\hline Patient 28 & $\mathrm{M}$ & 13 & Yes & Yes & Left upper sternal border & No \\
\hline Patient 29 & M & 4 & Yes & No & Left upper sternal border & No \\
\hline Patient 30 & $\mathrm{~F}$ & 2 & Yes & Yes & Under left clavicle & Yes \\
\hline
\end{tabular}

ASD = atrial septal defect; $F$ = female; $M=$ male; $N A=$ not applicable; $O P=$ ostium primum; $O S$ = ostium secundum; PDA = patent ductus arteriosus; VSD = ventricular septal defect. 
intensity (right upper sternal border, left upper sternal border, low to middle left sternal border, under left clavicle, apex, back), and radiation (yes, no). Changes in intensity (higher, lower, or comparable) between supine and standing positions were also evaluated when a murmur was present in both positions. After this physical examination had been completed, all children then had an echocardiogram to assess the presence or absence of cardiac anomalies that could explain the murmur. Trivial valvular regurgitations and patent foramen ovale were considered to be physiologic and not to explain the murmur.

Descriptive data are presented as means \pm standard deviations, and diagnostic performance data are presented as values with $95 \%$ confidence intervals. We used the Student $t$ test to compare noncategorical data and the $\chi^{2}$ or Fischer exact test to compare categorical

\begin{tabular}{ccl} 
Timing & Symptoms & \multicolumn{1}{c}{ Cardiac Disease } \\
\hline Systolic & No & Muscular VSD \\
Systolic & No & ASD OS \\
Systolic & Yes & ASD OS \\
Systolic & No & Mitral regurgitation \\
Systolic & No & Mitral regurgitation \\
Systolic & No & ASD OS \\
Systolic & Yes & Mitral regurgitation \\
Systolic & No & Mitral regurgitation \\
Systolic & No & Aortic stenosis \\
Systolic & No & ASD OS \\
Systolic & No & ASD OP \\
Systolic & No & Pulmonary stenosis \\
Systolic & No & Mitral regurgitation \\
Systolic & No & Coronary-to-pulmonary artery fistula \\
Systolic & No & Perimembranous VSD \\
Systolic & Yes & Muscular VSD \\
Systolic & No & Muscular VSD \\
Systolic & Yes & Muscular VSD, ASD OS \\
Systolic & Yes & Muscular VSD \\
Systolic & No & Tricuspid regurgitation \\
Systolic & No & Mitral regurgitation \\
Systolic & No & Coarctation of aorta \\
Systolic & No & Mitral regurgitation \\
Systolic & No & Aortic stenosis \\
Systolic & No & ASD OS \\
Systolic & No & Aortic stenosis \\
Systolic & Yes & ASD OP \\
Systolic & No & ASD OP \\
Systolic & Yes & ASD OS \\
Continuous & No & PDA \\
& &
\end{tabular}

data. Analyses were performed using Prism version 5 (GraphPad Software, Inc). Statistical significance was defined as a $P<.05$.

\section{RESULTS}

Among the 194 children studied, 30 (15\%) had abnormal findings on echocardiogram that explained the murmur. The cardiac diseases diagnosed were atrial septal defects (ASDs) in 9 children, ventricular septal defects (VSDs) in 5, ASD associated with VSD in 1, sonographically important mitral regurgitation in 7 , tricuspid regurgitation in 1 , aortic valve stenosis in 3 , pulmonary valve stenosis in 1 , coarctation of the aorta in 1, patent ductus arteriosus in 1, and coronaryto-pulmonary artery fistula in 1 . The clinical and echocardiographic characteristics of the children are shown in Table 1.

Persistence of the murmur on standing, the absence of a decrease of its intensity, location on the left upper sternal border or at the apex, and presence of radiation were significantly associated with a pathologic murmur (Table 2).

Overall, 100 children had complete disappearance of their murmur when they stood up. Within this group, only 2 (2\%) had an abnormal echocardiogram. One, a girl aged 13 years, had an ASD, and needed percutaneous closure of the defect. Her murmur was located on the left upper sternal border without radiation. The other, a boy aged 12 years, had a trivial muscular VSD, and required neither intervention nor specialized follow-up. His murmur was located at the low to middle left sternal border without radiation.

The complete disappearance of murmur on standing excluded a pathologic murmur with a positive predictive value of $98 \%$ (95\% CI, 93\%-100\%), a specificity of $93 \%(95 \% \mathrm{CI}, 78 \%-99 \%)$, and a sensitivity of $60 \%$ (95\% CI, 52\%-67\%) (Table 3). None of the conventionally used clinical features of physiologic murmur that we tested had a better positive predictive value for excluding a pathologic murmur.

\section{DISCUSSION}

In this era of highly technical medicine, physical examination should remain the first step of diagnosis. Most heart murmurs in children are physiologic (innocent), ${ }^{12,13}$ and these murmurs can be distinguished from pathologic (organic) murmurs by critical clinical assessment. ${ }^{7,14}$ Too many children, however, are referred to pediatric cardiologists for fear of missing a cardiac disease.

In our study, $85 \%$ of children aged 2 to 18 years referred to a cardiologist for heart murmur did not have a cardiac disease, showing the lack of a basic 


\begin{tabular}{|c|c|c|c|}
\hline Characteristic & $\begin{array}{l}\text { Pathologic } \\
\text { Murmur } \\
(n=30)\end{array}$ & $\begin{array}{c}\text { Physiologic } \\
\text { Murmur } \\
(n=164)\end{array}$ & $P$ Value \\
\hline Age, y & $7.4 \pm 3.8$ & $6.2 \pm 3.3$ & .07 \\
\hline \multicolumn{4}{|l|}{ Sex, \% (No.) } \\
\hline Male & $57(17)$ & $64(105)$ & .53 \\
\hline Female & $43(13)$ & $36(59)$ & \\
\hline Symptoms, \% (No.) & & & 1.00 \\
\hline Yes & $20(6)$ & $9(14)$ & $<.001$ \\
\hline No & $80(24)$ & $91(150)$ & \\
\hline \multicolumn{4}{|l|}{$\begin{array}{l}\text { Murmur present in standing posi- } \\
\text { tion, \% (No.) }\end{array}$} \\
\hline Yes & $93(28)$ & $40(66)$ & $<.001$ \\
\hline No & $7(2)$ & $60(98)$ & \\
\hline \multicolumn{4}{|l|}{$\begin{array}{l}\text { Murmur intensity decreased in } \\
\text { standing position, \% (No.) }\end{array}$} \\
\hline Yes & $43(12)$ & $80(53)$ & $<.001$ \\
\hline No & $57(16)$ & $20(13)$ & \\
\hline \multicolumn{4}{|l|}{ Murmur timing, \% (No.) } \\
\hline Systolic & $97(29)$ & $100(164)$ & .16 \\
\hline Diastolic & $0(0)$ & $0(0)$ & \\
\hline Continuous & $3(1)$ & $0(0)$ & \\
\hline \multicolumn{4}{|l|}{ Murmur location, \% (No.) } \\
\hline Right upper sternal border & $13(4)$ & $6(9)$ & .76 \\
\hline Left upper sternal border & $7(11)$ & $10(16)$ & $<.001$ \\
\hline Low to middle left sternal border & $33(10)$ & $82(126)$ & $<.001$ \\
\hline Apex & $13(4)$ & $2(3)$ & $<.01$ \\
\hline Under left clavicle & $4(1)$ & $0(0)$ & .16 \\
\hline \multicolumn{4}{|l|}{ Murmur radiation, \% (No.) } \\
\hline Yes & $33(10)$ & $15(25)$ & $<.05$ \\
\hline No & $67(20)$ & 85 (139) & \\
\hline
\end{tabular}

and reliable clinical measure to reassure primary care physicians of the absence of cardiac disease in pediatric patients with heart murmur. Physiologic murmurs result from normal blood flow through the heart and great vessels. Disappearance of these murmurs on a change in position from supine to standing is due to decreased venous return, left ventricular chamber size, and stroke volume. ${ }^{15}$ We found that murmurs completely disappeared on standing in more than one-half of the children referred in our study, and this feature predicted the absence of cardiac disease with a high positive predictive value of $98 \%$. Only 2 children with disappearing murmurs had an abnormal echocardiogram, and just 1 of them needed further intervention, whereas the other did not need follow-up. We have therefore demonstrated that the disappearance of a murmur on standing is a valuable clinical feature to predict the absence of cardiac pathology. This objective clinical sign could help primary care physicians manage cardiac murmur, and avoid both unneeded costly, time-consuming referrals to the specialist and parental anxiety.

Clinical assessment to distinguish pathologic from physiologic murmur in children is taught in medical school. Physiologic murmur is characterized by systolic timing, low intensity, decreased intensity or disappearance on standing, low to middle left sternal border location, lack of radiation, and absence of associated symptoms. ${ }^{7-9,16}$ Several studies, however, have shown that the diagnostic accuracy of clinical assessment of heart murmurs by primary care physicians is poor and has not been sufficiently improved by an educational strategy to reduce unnecessary referrals and misdiagnosis. ${ }^{4,5,17-20}$ Some attributes in the description of murmurs, such as intensity, quality, or the presence of a click, either are highly subjective or require considerable experience to identify them. Primary care physicians and pediatricians thus prefer to refer their patients for fear of making mistakes concerning the murmur.

We propose a very basic, highly reliable, and objective clinical test to rule out underlying cardiac disease. Even if sensitivity of this test is low $(60 \%)$, it would have decreased the number of referrals to pediatric cardiologists for murmur by more than one-half, reducing the workload of a pediatric cardiol-
Table 3. Diagnostic Performance of Clinical Characteristics for Excluding a Pathologic Murmur

\begin{tabular}{lccc}
\hline Characteristic & $\begin{array}{c}\text { PPV, \% } \\
\mathbf{( 9 5 \% ~ C l )}\end{array}$ & $\begin{array}{c}\text { Specificity, \% } \\
\mathbf{( 9 5 \% ~ C l )}\end{array}$ & $\begin{array}{c}\text { Sensitivity, \% } \\
\mathbf{( 9 5 \% ~ C l )}\end{array}$ \\
\hline $\begin{array}{l}\text { Disappearance on standing } \\
\text { Conventionally used characteristics } \\
\quad \text { Low to middle left sternal border } \\
\quad \text { location }\end{array}$ & $98(93-100)$ & $93(78-99)$ & $60(52-67)$ \\
$\quad \begin{array}{l}\text { Diminution or disappearance on } \\
\quad \text { standing }\end{array}$ & $91(86-95)$ & $53(34-72)$ & $90(85-94)$ \\
$\quad$ No radiation & $87(81-92)$ & $33(17-53)$ & $85(78-90)$ \\
$\quad$ No symptoms & $86(80-91)$ & $20(7-39)$ & $91(86-95)$ \\
$\quad$ Systolic timing & $85(79-90)$ & $3(0-17)$ & $100(98-100)$ \\
\hline PPV positive predictive value. & & & \\
\hline
\end{tabular}


ogy unit having limited professional resources. ${ }^{21}$ Moreover, substantial health care savings would be expected because of the decreased number of consultations and echocardiograms. ${ }^{22}$ According to North American recommendations, echocardiograms should be performed only to assess a cardiac murmur when there is a family history of heart disease, cardiac symptoms, or abnormal clinical findings. ${ }^{23}$ Nevertheless, $40 \%$ of children who have a physiologic murmur still undergo echocardiography in some American hospitals. ${ }^{24}$

In our study, a girl aged 13 years with an ASD had disappearance of her murmur while standing. Indeed, contrary to other cardiac defects, ASD-related murmur is functional, due to increased blood flow through the pulmonary valve. It is similar to a physiologic murmur, as it is proto-systolic and discrete, but located in the left upper sternal border and often associated with an abnormal fixed split of the second sound. ${ }^{25}$ ASD is probably the only cardiac disease with a murmur that may disappear on standing. The location, associated sounds, common symptoms, and unusual persistence of the murmur at each auscultation, however, may help pediatricians to distinguish between an ASD-related and a physiologic murmur.

Electronic stethoscopes coupled with automated phono-spectrographic analysis of heart murmurs have been recently developed. These systems can distinguish between physiologic and pathologic murmurs with excellent sensitivity and specificity, ${ }^{26-29}$ but have been tested only by pediatric cardiologists and not by primary care physicians. The clinical standing test that we report here had lower sensitivity for the diagnosis of physiologic murmurs, as $40 \%$ of children with these murmurs were not correctly classified. It is easily and rapidly performed, however, and does not have any associated cost for acquiring a new device.

This study has limitations. Although we selected the most objective clinical features of murmurs (intensity, superimposed noises, and quality were not considered to be objective criteria), heart auscultation remains subjective, and we did not evaluate the reproducibility of the clinical features studied among the clinicians who participated in the study. Similarly, we did not verify the reproducibility of murmur characterization between pediatric cardiologists and primary care physicians (pediatricians, family doctors, residents). It would be of great interest to know whether the referring primary care physicians would have achieved the same results.

In conclusion, the distinction between a physiologic and pathologic heart murmur remains challenging for primary care physicians and pediatricians, despite well-known and widely taught criteria of physiologic murmurs. Children with physiologic murmurs are too often referred for costly cardiac investigations because primary care physicians fear missing a cardiac disease. The complete disappearance of an isolated heart murmur on standing in otherwise healthy children aged 2 to 18 years without a family history is a valuable clinical test to exclude a pathologic cardiac murmur and avoid referral to a cardiologist. A larger study is necessary to confirm the value of this clinical tool, with comparison of its reproducibility between pediatric cardiologists and primary care physicians.

To read or post commentaries in response to this article, see it online at http:I/www.AnnFamMed.org/content/15/6/523.

Key words: heart murmur; heart defects, congenital; children; auscultation; primary care; practice-based research

Submitted January 10, 2017; submitted, revised, March 23, 2017; accepted April 11, 2017.

\section{References}

1. Hoffman JIE, Kaplan S. The incidence of congenital heart disease. J Am Coll Cardiol. 2002;39(12):1890-1900.

2. Ainsworth S, Wyllie JP, Wren C. Prevalence and clinical significance of cardiac murmurs in neonates. Arch Dis Child Fetal Neonatal Ed. 1999;80(1):F43-F45.

3. Misra M, Mittal M, Verma AM, et al. Prevalence and pattern of congenital heart disease in school children of eastern Uttar Pradesh. Indian Heart J. 2009;61(1):58-60.

4. Mangione S, Nieman LZ. Cardiac auscultatory skills of internal medicine and family practice trainees. A comparison of diagnostic proficiency. JAMA. 1997;278(9):717-722.

5. Haney I, Ipp M, Feldman W, McCrindle BW. Accuracy of clinical assessment of heart murmurs by office based (general practice) paediatricians. Arch Dis Child. 1999;81(5):409-412.

6. Rajakumar K, Weisse M, Rosas A, et al. Comparative study of clinical evaluation of heart murmurs by general pediatricians and pediatric cardiologists. Clin Pediatr (Phila). 1999;38(9):511-518.

7. Chantepie A, Soulé N, Poinsot J, Vaillant MC, Lefort B. [Heart murmurs in asymptomatic children: When should you refer?]. Arch Pediatr. 2016;23(1):97-104.

8. Smythe JF, Teixeira OH, Vlad P, Demers PP, Feldman W. Initial evaluation of heart murmurs: are laboratory tests necessary? Pediatrics. 1990;86(4):497-500.

9. Frank JE, Jacobe KM. Evaluation and management of heart murmurs in children. Am Fam Physician. 2011;84(7):793-800.

10. Geggel RL, Horowitz LM, Brown EA, Parsons M, Wang PS, Fulton DR. Parental anxiety associated with referral of a child to a pediatric cardiologist for evaluation of a Still's murmur. J Pediatr. 2002; 140(6):747-752.

11. Bårdsen T, Sørbye MH, Trønnes H, Greve G, Berg A. Parental anxiety related to referral of childhood heart murmur; an observational/ interventional study. BMC Pediatr. 2015;15:193.

12. McLaren MJ, Lachman AS, Pocock WA, Barlow JB. Innocent murmurs and third heart sounds in Black schoolchildren. Br Heart J. 1980;43(1):67-73.

13. Van Oort A, Hopman J, De Boo T, Van Der Werf T, Rohmer J, Daniëls $O$. The vibratory innocent heart murmur in schoolchildren: a case-control Doppler echocardiographic study. Pediatr Cardiol. 1994;15(6):275-281. 
14. McCrindle BW, Shaffer KM, Kan JS, Zahka KG, Rowe SA, Kidd L. Cardinal clinical signs in the differentiation of heart murmurs in children. Arch Pediatr Adolesc Med. 1996;150(2):169-174.

15. Salazar SA, Borrero JL, Harris DM. On systolic murmurs and cardiovascular physiological maneuvers. Adv Physiol Educ. 2012;36(4): 251-256.

16. Newburger JW, Rosenthal A, Williams RG, Fellows K, Miettinen OS. Noninvasive tests in the initial evaluation of heart murmurs in children. N Engl J Med. 1983;308(2):61-64.

17. Gaskin PR, Owens SE, Talner NS, Sanders SP, Li JS. Clinical auscultation skills in pediatric residents. Pediatrics. 2000;105(6):1184-1187.

18. Mangione S, Nieman LZ, Gracely E, Kaye D. The teaching and practice of cardiac auscultation during internal medicine and cardiology training. A nationwide survey. Ann Intern Med. 1993;119(1):47-54.

19. Roy D, Sargeant J, Gray J, Hoyt B, Allen M, Fleming M. Helping family physicians improve their cardiac auscultation skills with an interactive CD-ROM. J Contin Educ Health Prof. 2002;22(3):152-159.

20. Vukanovic-Criley JM, Criley S, Warde CM, et al. Competency in cardiac examination skills in medical students, trainees, physicians, and faculty: a multicenter study. Arch Intern Med. 2006;166(6):610-616.

21. Murugan SJ, Thomson J, Parsons JM, Dickinson DF, Blackburn ME, Gibbs JL. New outpatient referrals to a tertiary paediatric cardiac centre: evidence of increasing workload and evolving patterns of referral. Cardiol Young. 2005;15(1):43-46.

22. Danford DA, Nasir A, Gumbiner C. Cost assessment of the evaluation of heart murmurs in children. Pediatrics. 1993;91(2):365-368.

23. Campbell RM, Douglas PS, Eidem BW, Lai WW, Lopez L, Sachdeva R. ACC/AAP/AHA/ASE/HRS/SCAI/SCCT/SCMR/SOPE 2014 appropriate use criteria for initial transthoracic echocardiography in outpatient pediatric cardiology: a report of the American College of Cardiology Appropriate Use Criteria Task Force, American Academy of Pediatrics, American Heart Association, American Society of Echocardiography, Heart Rhythm Society, Society for Cardiovascular Angiography and Interventions, Society of Cardiovascular Computed Tomography, Society for Cardiovascular Magnetic Resonance, and Society of Pediatric Echocardiography. J Am Coll Cardiol. 2014; 64(19):2039-2060.

24. Frias PA, Oster M, Daley PA, Boris JR. Outpatient echocardiography in the evaluation of innocent murmurs in children: utilisation benchmarking. Cardiol Young. 2016;26(3):499-505.

25. Muta $H$, Akagi T, Egami K, et al. Incidence and clinical features of asymptomatic atrial septal defect in school children diagnosed by heart disease screening. Circ J. 2003;67(2):112-115.

26. DeGroff CG, Bhatikar S, Hertzberg J, Shandas R, Valdes-Cruz L, Mahajan RL. Artificial neural network-based method of screening heart murmurs in children. Circulation. 2001;103(22):2711-2716.

27. Dahl LB, Hasvold P, Arild E, Hasvold T. Heart murmurs recorded by a sensor based electronic stethoscope and e-mailed for remote assessment. Arch Dis Child. 2002;87(4):297-301.

28. Lee C, Rankin KN, Zuo KJ, Mackie AS. Computer-aided auscultation of murmurs in children: evaluation of commercially available software. Cardiol Young. 2016;26(7):1359-1364.

29. Lai LSW, Redington AN, Reinisch AJ, Unterberger MJ, Schriefl AJ. Computerized Automatic Diagnosis of Innocent and Pathologic Murmurs in Pediatrics: A Pilot Study. Congenit Heart Dis. 2016;11(5): 386-395. 